\title{
Effect of a rapeseed oil derived pour point depressant on the flow properties of the waxy oil from Changqing Oilfield
}

\author{
Yongzhen Wang ${ }^{1}$, Guibin $\mathrm{Liu}^{2}$, Xiaoyu Zhou ${ }^{3}$, Qingzhu Zhng ${ }^{2}$, Wei Jiang ${ }^{2}$, Chuanghui Han ${ }^{2}$, Sitong Huo ${ }^{1}$, Yubo Lian ${ }^{2, *}$ \\ Sanbao Dong ${ }^{4}$ \\ ${ }^{1}$ The First Oil Delivery Office of Changqing Oilfield, Xi'an Shaanxi, 710068, China \\ ${ }^{2}$ Xi' an Changqing Chemical Group Co. Ltd, Xi'an Shaanxi, 710068, China \\ ${ }^{3}$ The Third Oil Delivery Office of Changqing Oilfield, Xi'an Shaanxi, 710068, China \\ ${ }^{4}$ Xi' an Key Laboratory of Tight oil (Shale oil) Development, Xi'an Shiyou University, Xi'an, 710 065, China
}

\begin{abstract}
In this paper, rapeseed oil was modified with diethylenetriamine to obtain a vegetable oil-derived pour point depressant (PPD), which was used to reduce the pour point and improve the flowability of the crude oil (from Changqing Oilfield), which has a high content of paraffin. Various instruments such as differential scanning calorimetry (DSC), polarized optical microscopy (POM), and a viscometer were used to investigate the performance of the PPD. The results showed that with the introduction of PPD into the waxy oil sample, the pour point of which could be significantly lowered from $20.0{ }^{\circ} \mathrm{C}$ to $13.2{ }^{\circ} \mathrm{C}$. At $23{ }^{\circ} \mathrm{C}$, the viscosity reduction rate of the oil sample was $68 \%$ in the presence of $500 \mathrm{mg} / \mathrm{kg}$ PPD. The wax morphology observation also confirmed that the formation and growth of the wax crystals could be significantly delayed and restrained. The results supported that the PPD synthesized in this paper could effectively improve the flowability of the waxy oil from Changqing Oilfield.
\end{abstract}

Keywords: Waxy oil, pour point depressant, vegetable oil, wax crystal.

\section{Introduction}

Flow assurance challenges of petroleum pipelines can be caused by asphaltenes, paraffin wax, scales, and gas hydrate[1]. The blockages of wells and pipelines during the production from shale reservoirs (e.g., Changqing Oilfield, China) are usually attributed to the deposition and buildup of wax crystals in the production liquids.

The wax from crude oil is a mixture of linear paraffins, iso-paraffins and cyclo-paraffins with various carbon numbers (from 18-65)[2]. The deposition of the wax in production liquids occurs below the wax appearance temperature (WAT), causing increased viscosity of the hydrocarbon liquids and consequent interrupt of the production.

Temperature, the composition of hydrocarbon liquids, flowing rate and surface property of the pipeline wall have a great influence on the deposition and buildup of the wax crystals. There are two parameters in paraffin wax deposition, WAT and gel formation temperature (GFT)[3]. During the production, the waxy crude oils are extracted from reservoirs to pipelines, if the temperature of the pipeline wall is lower than the WAT of the waxy oil, the decrease in temperature would facilitate the formation and deposition of wax crystals on the wall surface. The temperature gradient and even the concentration gradient between the bulk liquids and wall surface would certainly promote the buildup of wax layer on the wall surface until the GFT of the production liquids is reached. For this reason, the pressure drop would also be increased, which will significantly raise the risk of pipeline plugging. The temporarily deposited wax crystals would be decomposed by the shearing effect of the production liquids. However, during the shale oil production, the low flow rates (which is more likely) of the production liquids can not delay/prevent the deposition.

The chemical inhibitors used for mitigating wax deposition, which is a promising method, can be split into two categories: crystal modifiers and dispersants[4-6]. The main advantages of dosing these chemicals are low dosage requirement and the simple operation without the need to shut down the production. Crystal modifiers are oil-soluble copolymers containing hydrocarbon branches with certain carbon numbers (needs to be optimized for improving the inhibiting performance) and hydrophilic groups. The hydrocarbon branches can participate in the formation of the wax crystals and herein provide steric hindrance that prevents the aggregation of the wax crystals. Therefore, the growth of the wax crystals can be effectively disrupted and retarded. Wax dispersants are usually inter-surface active agents containing wax-philic groups and water-philic groups. Therefore, the wax dispersants can be adsorbed onto the wax surface and deposition surfaces, altering the wettability of these

* Corresponding author: dicpyblian@163.com 
surfaces to water-wet conditions, and preventing further aggregation and buildup of these wax crystals[7-9].

There are many factors affecting the performance of the chemical inhibitors, for example, the type of the hydrocarbon fluid, properties of the wall surfaces, and the crude oil-chemical interactions. The chemicals could reduce the pour point and viscosity of the waxy crude oil, and also alter the morphology of the wax crystals. In this study, various instruments such as differential scanning calorimetry (DSC), polarized optical microscopy (POM), and a viscometer were used to investigate the performance of the rapeseed oil-derived pour point depressants (PPD). The PPD was obtained by the amination reaction between rapeseed oil and diethylenetriamine.

\section{Experimental section}

\subsection{Materials}

The waxy crude oil was provided by Chnagqing Oilfield, China. The SARA data of the oil sample is offered in Table 1. The SARA components were separated using the method described in Chen's works [10]. A commercial copolymer, EVA, used as a PPD, and diethylenetriamine (with a purity of 97\%) were from Aladdin (Shanghai).

Table 1 The properties of the waxy oil from Nanliang Block (Changqing Oilfield)

\begin{tabular}{cccccc}
\hline $\begin{array}{c}\text { Pour } \\
\text { point } \\
\left({ }^{\circ} \mathrm{C}\right)\end{array}$ & $\begin{array}{c}\mathrm{P} 20 \\
\left(\mathrm{~g} \cdot \mathrm{cm}^{-}\right. \\
3\end{array}$ & $\begin{array}{c}\text { Saturates } \\
(\%)\end{array}$ & $\begin{array}{c}\text { Aromatics } \\
(\%)\end{array}$ & $\begin{array}{c}\text { Resins } \\
(\%)\end{array}$ & $\begin{array}{c}\text { Asphaltenes } \\
(\%)\end{array}$ \\
\hline 20.0 & 0.87 & 51.66 & 33.12 & 12.01 & 3.21 \\
\hline
\end{tabular}

\subsection{Preparation of the pour point depressant PPD}

The PPD was prepared by the amination of rapeseed oil by diethylenetriamine. In this paper, the rapeseed oil and diethylenetriamine (with a mol ratio of 1:1) were reacted in the toluene phase for 4 hours under flush conditions. After the reaction, the toluene was removed under vacuum conditions, after the separation of the toluene from the mixtures, the products (see Fig. 1) were obtained.

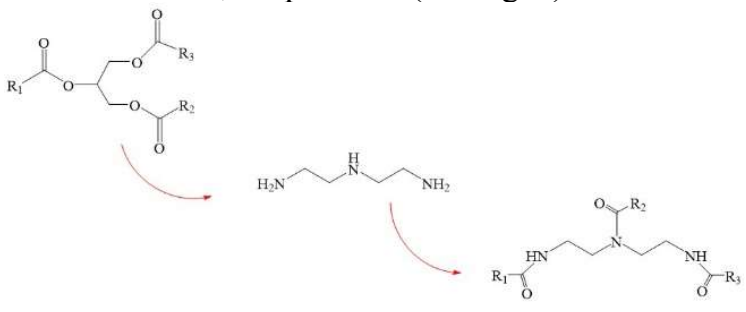

Fig. 1 The preparation of PPD through the amination of rapeseed oil

\subsection{Viscosity measurement}

The viscosity of each oil sample with and without PPD was measured using a viscometer (Brookfield II, USA). In each measurement, the temperature of the oil sample was increased from room temperature to $30{ }^{\circ} \mathrm{C}$. Each measurement was repeated three times to keep the accuracy of the results.

\subsection{Pour point measurement}

Based on the method described in the standard of ASTM D5853 (Standard Test Method for Pour Point of Crude Oils), each oil sample's pour point was tested at least three times to find the average value of the pour point.

\subsection{Microscope observation of the morphology of wax crystals}

After the separation of saturates from the waxy crude oil sample, the saturate sample was placed on a glass slide, which was put on the stage of the polarized microscopy(BX41-P Olympus, Japan). The temperature of the stage was controlled by an externally connected chiller. Before each test, the saturate sample was kept at $50{ }^{\circ} \mathrm{C}$ (higher than the melting point of the paraffin wax) for at least $15 \mathrm{~min}$ to avoid the influence of already-formed crystals. To promote the formation of the wax crystals, the temperature of the sample was reduced from $50{ }^{\circ} \mathrm{C}$ to $10{ }^{\circ} \mathrm{C}$ at a cooling rate of $4{ }^{\circ} \mathrm{C} / \mathrm{min}$. The sample was controlled at $10{ }^{\circ} \mathrm{C}$ to keep the growth of the wax crystals. During the whole test, the morphology of the wax crystals was automatically recorded.

\section{Results and discussion}

\subsection{Performance of PPD in reducing the viscosity of crude oil}

The wax inhibitors mitigate the risk of pipeline blockage caused by wax deposition via the reduction in viscosity and pour point. In this section, the performance of PPD was analyzed compared with the performance of EVA. In each test, wax inhibitor (EVA or PPD) with a dosage of $500 \mathrm{mg} / \mathrm{kg}$ was mixed with the waxy crude oil. Then the viscosity of each mixed oil sample was measured. As shown in Fig 3, without wax inhibitor, the viscosity of the crude oil decreases from $44000 \mathrm{mPa} \cdot \mathrm{s}$ to $902 \mathrm{mPa} \cdot \mathrm{s}$ in the temperature range of $23{ }^{\circ} \mathrm{C}-28{ }^{\circ} \mathrm{C}$. With the presence of $500 \mathrm{mg} / \mathrm{kg} \mathrm{PPD}$, the corresponding viscosity of the sample was decreased from $20100 \mathrm{mPa} \cdot \mathrm{s}$ to $122 \mathrm{mPa} \cdot \mathrm{s}$ in the temperature range of $23{ }^{\circ} \mathrm{C}-28{ }^{\circ} \mathrm{C}$, indicating that the PPD can effectively reduce the viscosity of the crude oil. It should be noted that the oil sample with $500 \mathrm{mg} / \mathrm{kg}$ was higher than that of the oil sample with $500 \mathrm{mg} / \mathrm{kg}$ PPD. The performance of EVA was slightly lower than that of PPD as can be seen from Fig 2. 


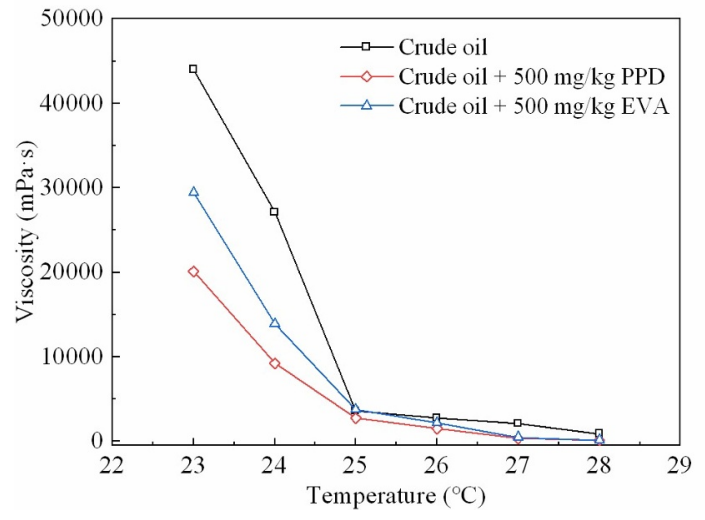

Fig 2 Effect of PPD and EVA on the viscosity of the crude oil

For the effect of PPD's dosage on viscosity reduction, the viscosity of the oil sample gradually decreases with the increase in the PPD's dosage in the waxy crude oil as can be drawn from Fig 3. At the dosage of $500 \mathrm{mg} / \mathrm{kg}$, the viscosity of the crude oil can be lowered to $122 \mathrm{mPa} \cdot \mathrm{s}$ at $28^{\circ} \mathrm{C}$.

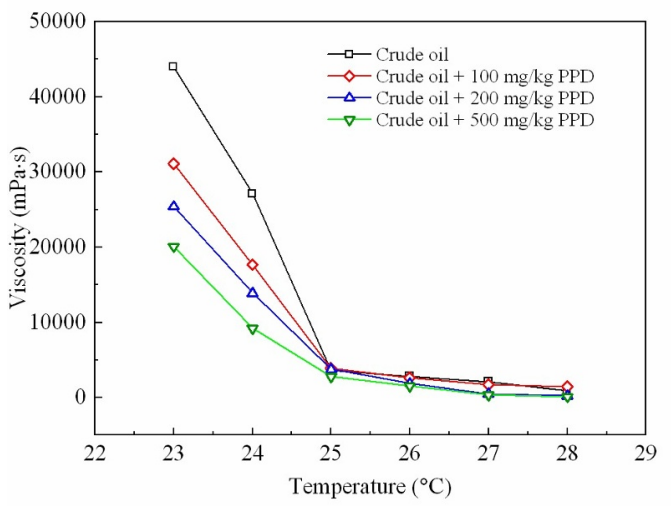

Fig 3 Effect of PPD's dosage on the viscosity of the crude oil

\subsection{Performance of PPD in reducing the pour point of crude oil}

The effect of PPD on the pour point of the oil sample was listed in Table 2. After the introduction of $500 \mathrm{mg} / \mathrm{kg}$ PPD in the crude oil sample, the pour point of which can be reduced to $13.2^{\circ} \mathrm{C}$, which was slightly lower than the pour point $\left(14.4^{\circ} \mathrm{C}\right)$ of the oil sample with EVA at the same dosage. This result verified that the efficiency of PPD was superior to EVA.

Table 2 Efficiency of wax inhibitors on the pour point of waxy oil from Changqing Oilfield

\begin{tabular}{cccc}
\hline Sample & $\begin{array}{c}\text { Crude } \\
\text { oil }\end{array}$ & $\begin{array}{c}\text { Crude oil } \\
+500 \mathrm{mg} / \mathrm{kg} \\
\mathrm{EVA}\end{array}$ & $\begin{array}{c}\text { Crude oil } \\
+500 \mathrm{mg} / \mathrm{kg} \\
\mathrm{PPD}\end{array}$ \\
\hline $\begin{array}{c}\text { Pour point } \\
\left({ }^{\circ} \mathrm{C}\right)\end{array}$ & 20 & 14.4 & 13.2 \\
\hline
\end{tabular}

\subsection{Wax morphology analysis}

The effects of inhibitors on the morphology of wax crystal were present in Fig 4. Without chemical additive, a threedimensional network of sword-shaped crystals was observed. However, in the samples containing wax inhibitors, the wax crystals with limited sizes were dispersed in the saturates phase, no network of crystals can be found. These results confirmed that the PPD is a promising wax inhibitor that has a similar performance with EVA when tested with the waxy crude oil from Changqing Oilfield.
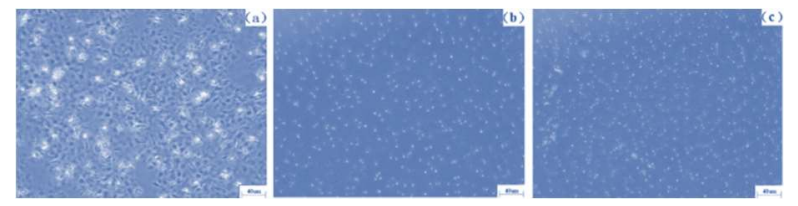

Fig 4. Physical appearances of (a): saturates, (b): saturates +500 $\mathrm{mg} / \mathrm{kg}$ EVA and (c): saturates $+500 \mathrm{mg} / \mathrm{kg}$ PPD

\section{Conclusions}

A wax inhibitor (PPD) was synthesized through the amination of rapeseed oil with diethylenetriamine. The PPD's efficiency in improving the flowability of the waxy oil sample from Changqing Oilfield was investigated. The pour point of the oil sample can be lowered from $20^{\circ} \mathrm{C}$ to $13.2{ }^{\circ} \mathrm{C}$ in the presence of $500 \mathrm{mg} / \mathrm{kg}$ PPD. At the same dosage of PPD, the viscosity of the oil sample can be lowered to $122 \mathrm{mPa} \cdot \mathrm{s}$ at $28{ }^{\circ} \mathrm{C}$. The wax crystals can be well dispersed in the saturates phase.

\section{Competing interests}

The authors declare that they have no competing interests.

\section{Acknowledgments}

The work was supported financially by the Open Fund of Shaanxi Key Laboratory of Carbon Dioxide Storage and Enhanced Oil Recovery (YJSYZX20SKF0008), Natural Science Basic Research Program of Shaanxi (Program No. 2020JQ-775), Scientific Research Program Funded by Shaanxi Provincial Education Department (Program No. 21JP094) and The Youth Innovation Team of Shaanxi Universities. And we thank the work of the Modern Analysis and Testing Center of Xi' an Shiyou University.

\section{References}

1. Kelland M.A. Production Chemicals for the Oil and Gas Industry, 1st Edition[M]. Boca Raton, CRC Press, 2008.

2. Lake L.W. Petroleum Engineering Handbook: Volume 1. General Engineering, SPE, ISBN: 978-155563-108-6.

3. Srivastava S.P., Saxena A.K., Tandon R.S., Shekher $\mathrm{V}$. Measurement and prediction of solubility of 
petroleum waxes in organic solvents[J]. Fuel, 1997, 76(7): 625-630.

4. Li L., Tinsley J., Adamson D.H., Pethica B.A., Huang J.S., Guo X. Improvement of oil flowability by assembly of comb-type copolymers with paraffin and asphaltene[J]. AIChE Journal, 2012, 58(7): 22542261.

5. Xu J., Xing S., Qian H., Chen S., Wei X., Zhang R., Guo X. Effect of polar/nonpolar groups in comb-type copolymers on cold flowability and paraffin crystallization of waxy oils[J]. Fuel, 2013, 103: 6006056.

6. Wei B. Recent advances on mitigating wax problem using polymeric wax crystal modifier[J]. Journal of Petroleum Exploration and Petroleum Technology, 2015, 5(4): 391-401.

7. Sun M., Naderi K., Firoozabadi A. Effect of crystal modifiers and dispersants on paraffin-wax particles in petroleum fluids[J]. SPE Journal, 2018, 24(01): SPE-191365-PA.

8. Dobbs J.B. A unique method of paraffin control in production operations[C]. SPE Rocky Mountain regional meeting, Society of Petroleum Engineers, SPE-55647-MS, 1999.

9. Kar T., Firoozabadi A. Mitigation of paraffin wax deposition and the effect of brine[C]. SPE Annual Technical Conference and Exhibition held in Calgary, Alberta, Canada. Society of Petroleum Engineers, SPE-196032-MS, 2019.

10. Chen G., Lin J., Hu W., Cheng C., Gu X., Du W., Zhang J. Characteristics of a crude oil composition and its in situ waxing inhibition behavior[J]. Fuel, 2018, 218: 213-217. 